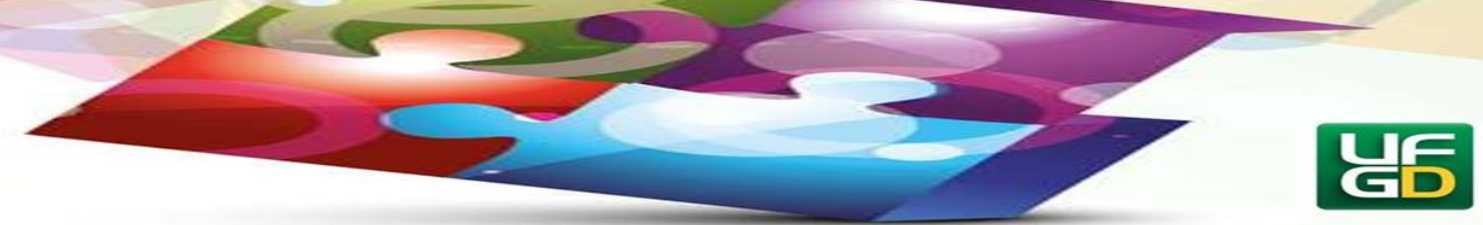

\title{
FORMAÇÃO DOCENTE PARA O USO DAS TECNOLOGIAS MÓVEIS NA ESCOLA: EM BUSCA DE NOVAS PROPOSTAS FORMATIVAS
}

\section{TEACHING FORMATION FOR THE USE OF MOBILE TECHNOLOGIES IN} SCHOOL: IN SEARCH OF NEW FORMATIVE PROPOSALS

\author{
Célia Regina de CARVALHO ${ }^{1}$
}

\begin{abstract}
Resumo: no presente artigo analisamos as contribuições de ações de formação continuada do ProInfo Intregrado que possibilitassem a integração de tecnologias digitais e móveis no processo de ensino e aprendizagem. Se refere a um estudo cujo objetivo geral consistia em analisar e avaliar a implementação de uma proposta de formação continuada envolvendo professores da rede pública do município de Naviraí-MS sobre o uso de tecnologias móveis na escola. A metodologia envolveu uma pesquisa qualitativa, na qual procedemos a um levantamento documental de materiais de cursos ofertados pelo Núcleo de Tecnologia Educacional, no período de 2010 a 2014. Os resultados demonstram que estas ações pretendem dotar gestores e professores de conhecimentos necessários para se apropriarem das tecnologias a fim de integrá-las no trabalho docente. Porém, são pensadas em nível nacional, na modalidade semipresencial, desconsiderando a realidade e peculiaridade das escolas instituições, bem como os variados níveis de apropriação dos participantes. Recomendamos a instauração de propostas formativas que considerem as demandas provenientes das instituições e as necessidades dos professores e que estejam ligadas à realidade pela qual estão inseridos.
\end{abstract}

Palavras-chave: Tecnologias Móveis. Escola. Ações de Formação. Professores.

Abstract: in this article we analyze the contributions of continuous formation actions of ProInfo Intregrado that allow the integration of digital and mobile technologies in the process of teaching and learning. It refers to a study whose general objective was to analyze and evaluate the implementation of a proposal of continuous formation teachers of the public network of the municipality of Naviraí-MS on the use of mobile technologies in school. The methodology involved a qualitative research, in which we proceeded to a documentary survey of course materials offered by the Educational Technology Center, from 2010 to 2014. The results demonstrate that these actions aim to provide managers and teachers with the necessary knowledge to appropriate the technologies in order to integrate them into teaching work. However, they are thought at the national level, in the semi-private modality, disregarding the reality and peculiarity of the institutions schools, as well as the varying levels of appropriation of the participants. We recommend the introduction of formative proposals that consider the demands coming from the

\footnotetext{
${ }^{1}$ Professora Adjunta da Fundação Universidade Federal de Mato Grosso do Sul (UFMS), câmpus de Naviraí. Doutora em Educação pela Universidade Estadual Paulista (UNESP), câmpus de Presidente Prudente-SP. E-mail: celia.carvalho@ufms.br.
} 


\section{HORIZONTES - REVISTA DE EDUCAÇÃO}

e-ISSN: 2318-1540

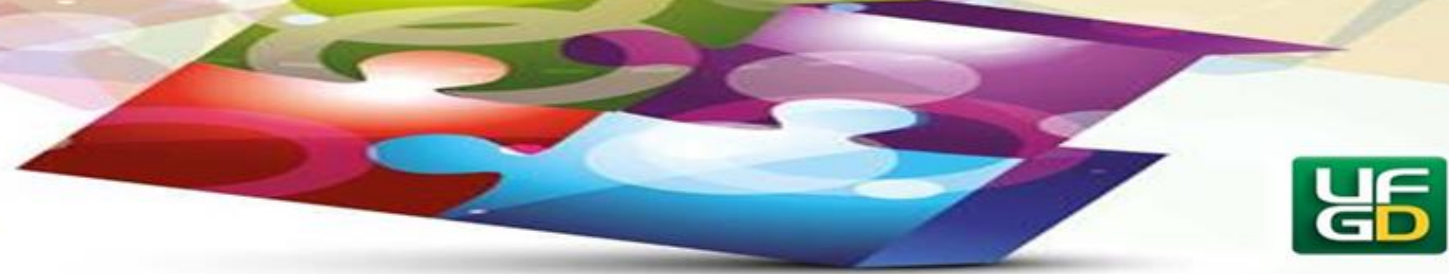

institutions and the needs of the teachers and that are linked to the reality by which they are inserted.

Keywords: Mobile Technologies. School. Formation Actions. Teachers.

\section{Introdução}

O presente artigo apresenta recorte de um estudo que resultou em uma tese de doutorado cujo objetivo geral consistia em analisar e avaliar a implementação de uma proposta de formação continuada envolvendo professores do ensino fundamental da rede pública do município de Naviraí - MS sobre o uso de tecnologias móveis na escola.

A proposta do estudo partiu do pressuposto de que os alunos da geração digital, provenientes das gerações $\mathrm{Z}^{2}$ e Alpha ${ }^{3}$ apresentam grande familiaridade com aparelhos móveis. De acordo com dados da pesquisa nacional por amostra de domicílios (PNAD) do Instituto Brasileiro de Geografia Estatística (IBGE, 2016), 94,6\% dos usuários com 10 anos ou mais de idade se conectaram a internet via celular. Este aparelho estava presente em 92,6\% dos 69,3 milhões de domicílios. Por conseguinte, a região Centro-Oeste, é a segunda do país em utilização da internet.

Com a expansão de aparelhos como celulares, tablets, notebooks, o acesso às informações provenientes das redes tem sido favorecido a pessoas de várias classes sociais. Por este motivo, a escola deve criar novos espaços voltados para as práticas educacionais mediadas pelas linguagens das tecnologias móveis que podem contribuir para elevar os níveis de educação do Brasil (SANTOS, 2012).

Por meio das tecnologias móveis as pessoas têm a possibilidade de acessar, produzir e publicar conteúdo. Neste sentido, "a escola ocupa um papel central na formação de indivíduos, na medida em que diante do excesso de informações dispersas e fragmentadas disponíveis nas redes, faz-se mister que os professores os orientem a fim de organizá-las de forma significativa" (CARVALHO, 2017, p. 2).

A inserção das tecnologias móveis na escola, em situações pedagógicas, ainda é alvo de algumas é incipiente. Não há um consenso por parte de gestores e professores sobre o seu

\footnotetext{
${ }^{2}$ Nascidos a partir do ano de 2000.

${ }^{3}$ Nascidos a partir do ano de 2010.
} 


\section{HORIZONTES - REVISTA DE EDUCAÇÃO}

potencial educativo. Isto decorre das insuficiências da formação inicial e continuada de professores. Neste sentido, torna-se imprescindível discutir sobre esta temática uma vez que a presença cada vez mais intensa das tecnologias móveis e as novas relações estabelecidas por elas no espaço escolar representam um grande desafio para a escola e os professores, na medida em que pressupõem o rompimento com padrões tradicionais de ensino que as concebem como simples ferramentas auxiliares do processo de ensino e aprendizagem (CARVALHO, 2017).

Surge, portanto, a necessidade da criação de políticas e/ou propostas formativas que propiciem aos professores, saberes que os capacitem a integrar as tecnologias móveis no trabalho docente. Neste recorte, analisamos as contribuições de ações de formação continuada do Programa Nacional de Formação Continuada em Tecnologia Educacional (ProInfo Intregrado) que possibilitam a integração de tecnologias digitais e móveis no processo de ensino e aprendizagem.

\section{A formação de professores no contexto da cibercultura}

A inserção das tecnologias móveis na escola tem alterado a dinâmica do processo de ensino e aprendizagem, uma vez que deve haver novos modos de exercer a docência. Mas como adquirir uma nova dinâmica de trabalho a fim de que surjam novas ações que possibilitem uma formação adequada a essa realidade?

A formação docente para o uso das tecnologias pressupõe que os professores ressignifiquem o seu trabalho. Concebemos o termo ressignificação do trabalho docente a partir da conceituação de Tardif e Lessard (2005, p. 45) que o define como um trabalho interativo que envolve "aspectos formais e informais e se trata, portanto, ao mesmo tempo, de um trabalho flexível e codificado, controlado e autônomo, determinado e contingente".

O ensino surge como uma tarefa fortemente marcada pelas interações humanas, resultando em um saber "relacionado com a pessoa e a identidade dos professores, com suas experiências de vida e com a sua história profissional, com as suas relações com os alunos em sala de aula e com os outros atores escolares na escola" (TARDIF, 2005, p. 11).

Considerando o exemplo das tecnologias móveis, em especial os laptops educacionais do Projeto Um computador por aluno, Almeida et al., (2012, p. 7077) aponta para a importância de a formação de professores proporcionar a ressignificação do trabalho pedagógico, tendo em 


\section{HORIZONTES - REVISTA DE EDUCAÇÃO}

vista a atuação do professor dentro da escola e em especial no interior da sala de aula. Tomando como exemplo os resultados de um estudo envolvendo o "Projeto UCA Formação Brasil" em escolas do estado de Tocantins, os autores asseveram que os professores têm buscado transformar "espaços escolares e não escolares em espaços com múltiplas zonas de desenvolvimento proximal" na medida em que os professores e gestores organizem o trabalho pedagógico de forma diferenciada. A esse respeito, ponderam que os processos de formação devam primar pelo movimento teoria à prática e prática à teoria, encorajando os professores a reverem suas práticas de modo a incorporarem as tecnologias móveis em seu trabalho docente.

A escola se constitui como um local privilegiado para iniciar a inclusão digital, espaço este que favorece a "[...] inserção dos jovens na cultura de seu tempo" (BONILLA, 2010, p. 44). Por conseguinte deve ser um espaço que oportunize aos jovens a vivência plena e crítica das redes sociais.

São apresentadas novas demandas para à escola e aos professores, isto é, aprender a “[...] conviver com as transformações que as tecnologias e mídias digitais provocam na sociedade e na cultura". Todas estas mudanças são trazidas para dentro das escolas. Os alunos, por sua vez, são pouco orientados sobre a forma de se relacionar educacionalmente com esses artefatos (ALMEIDA; SILVA, 2011, p. 5).

Pretto (2010, p. 79) acredita que

[...] a apropriação da cultura digital passa a ser fundamental, uma vez que já indica intrinsecamente um processo crescente de reorganização das relações sociais mediadas pelas tecnologias digitais, afetando em maior ou menor escala todos os aspectos da ação humana.

Deve haver, portanto, a implantação de políticas públicas que propiciem a apropriação criativa "dos meios digitais e dos seus objetos e, com isso, produzir mais e de forma diferenciada" (PRETTO, 2010, p. 79). Por esse motivo, torna-se indispensável formar professores que atuem como mediadores entre os jovens e a cultura digital tornando a escola um espaço "de produção, ampliação e multiplicação de culturas".

A incorporação das tecnologias digitais no trabalho docente pressupõe quatro dimensões debatidas por Almeida e Silva (2011, p. 6). A dimensão crítica pressupõe uma humanização do ato pedagógico e representa inicialmente uma opção política por parte do professor. Esta opção política se apoia "em valores e compromissos éticos que relacionam a teoria com a prática, a 


\section{HORIZONTES - REVISTA DE EDUCAÇÃO}

formação de educadores com o fazer pedagógico e o pensar sobre o fazer, o currículo com a experiência e com a emancipação humana".

A dimensão tecnológica envolve o domínio das tecnologias e de suas linguagens proporcionando ao professor explorar seus recursos e funcionalidades a fim de se familiarizar com as possibilidades de interação por meio deles e com isso adquira autonomia para desenvolver atividades pedagógicas que adotem as tecnologias digitais. Já a dimensão pedagógica "se refere ao acompanhamento de processo de aprendizagem do aluno, a busca de compreender sua história e universo de conhecimentos, valores, crença e modo de ser, estar e interagir com o mundo mediatizado pelos instrumentos culturais presentes em sua vida". A dimensão didática converge para o conhecimento que o professor dispõe em sua área de atuação, assim como as competências referentes aos conhecimentos mobilizados no desenvolvimento do seu trabalho (ALMEIDA; SILVA, 2011, p. 6).

Nesta vertente, a formação pode desempenhar mudanças significativas no trabalho docente, desde que vise a reconstrução da prática docente por meio da criação de estratégias que permitam "lidar ao mesmo tempo com as inovações oferecidas pelas tecnologias e com o compromisso da escola enquanto organização institucional" (PRADO; SILVA, 2009, p. 63). Por conseguinte, é importante que o processo de formação leve em conta os aspectos que se encontram relacionados com o contexto em que os professores atuam e favoreçam "a reflexão sobre a própria prática para compreendê-la e, possivelmente, reconstruí-la" (PRADO; SILVA, 2009, p. 63).

O incentivo para o desenvolvimento de posturas reflexivas e construtoras de saberes a partir da própria experiência dialoga com algumas ideias defendidas por Tardif (2005) ao assinalar que, dentre os saberes docentes, os experienciais resultam da experiência do professor e se referem ao conjunto de saberes adquiridos por meio da prática da profissão docente, servindo de referenciais para sua orientação profissional.

Torna-se importante fomentar condições para que os professores se sintam estimulados a recontextualizar os saberes para a utilização das tecnologias móveis em consonância com aqueles resultantes de sua experiência profissional. Assim, a formação enfatiza as experiências profissionais e as trocas de saberes no espaço escolar (TARDIF, 2005). Mas, qual seria esse tipo de formação, e em que sentido as políticas de formação como as provenientes do ProInfo Integrado poderiam contribuir para uma mudança significativa no trabalho dos professores? 


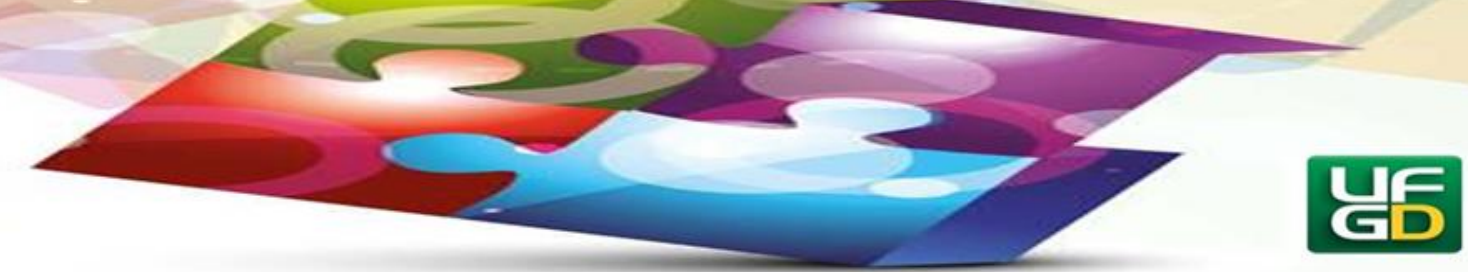

\section{Metodologia do estudo}

Para o desenvolvimento do estudo nos baseamos nos pressupostos de uma pesquisa qualitativa, de natureza descritivo-explicativa, que contemplou as seguintes etapas: $1^{\text {a }}$ ) levantamento documental de materiais de cursos ofertados pelo Núcleo de Tecnologia Educacional (NTE) do município de Naviraí - MS, no período de 2010 a 2014, voltadas para o uso das tecnologias móveis na escola; $2^{\text {a }}$ ) aplicação de questionário semiestruturado aplicado a 46 professores de escolas públicas do município com o objetivo de identificar e analisar o nível de formação e o contato em relação ao uso de tecnologias na escola; $3^{a}$ ) proposta de formação continuada (pesquisa intervenção) envolvendo um grupo de dez professoras da educação básica a fim de possibilitar a utilização das tecnologias móveis em situações pedagógicas.

Os dados apresentados neste artigo se referem a primeira parte do estudo na qual procedemos a um levantamento documental a fim de conhecermos a política de formação de professores promovida pelo ProInfo Integrado e oferecido pelos NTE do estado de Mato Grosso do Sul. A fim de procedermos ao esteC documental, elaboramos um quadro de análise que buscou mapear: a) os principais cursos ofertados pelo NTE; b) os principais objetivos e pressupostos contidos neles; c) o público-alvo, carga horária, estrutura curricular e os materiais de apoio; d) as principais ideias ou conceitos trabalhados durante o curso; e) a proposta pedagógica, metodologia e referencial teórico; c) a forma de avaliação e certificação dos participantes do curso;

\section{Análise dos principais cursos do ProInfo Intregrado do município pesquisado no período de 2010 a 2014}

As principais ações ofertadas pelo NTE foram: Introdução à Educação Digital, Tecnologias na Educação: Ensinando e aprendendo com as TIC; Elaboração de Projetos; Redes de Aprendizagem; Programa Um computador por aluno (PROUCA); Projeto Educação Digital (Política para computadores interativos e tablet) e Oficina Uso pedagógico do tablet.

Os três primeiros cursos (Educação Digital, Tecnologias na educação e Elaboração de Projetos) procuram aprofundar os conceitos relativos à inclusão digital culminando na 


\section{HORIZONTES - REVISTA DE EDUCAÇÃO}

e-ISSN: 2318-1540

integração das tecnologias na prática docente por meio do desenvolvimento de projetos integrados ao currículo da escola. A fim de dar continuidade aos conhecimentos abordados, o curso Redes de Aprendizagem foi elaborado a fim de que os cursistas adquirissem cada vez mais conhecimentos nesta área, como expresso no excerto a seguir: "[...] a maturidade construída nos cursos anteriores é a base para reflexões mais amplas acerca do papel da escola e dos professores frente à cultura digital, ainda mais nessa sociedade altamente tecnificada" (ARRIADA; RAMOS, 2013, p. 8).

Por conseguinte, eram propostas atividades práticas que envolviam "cenários mais desafiadores, como estruturação de políticas na escola e articulação comunitária para o uso crítico das tecnologias" (ARRIADA; RAMOS, 2013, p. 8).

Os cursos analisados tinham como público-alvo, os professores e gestores da educação básica. Este aspecto chama a atenção, pois busca envolver outros agentes escolares. Entendemos, com isso, que não são somente os professores devem mudar a sua forma de ver as tecnologias, pois “a incorporação das TIC nas práticas escolares passa necessariamente, por transformações no currículo da escola e na forma como esta concebe o uso destes recursos nas situações de ensino e aprendizagem" (CARVALHO, 2017, p. 143).

Assim sendo, é preciso promover a disseminação das tecnologias tanto nas ações pedagógicas quanto na gestão escolar, sobretudo,

[...] como instrumento para o acompanhamento das distintas atividades da escola, a tomada de decisões compartilhada, a comunicação interna, a publicação de informações sobre a escola, a integração com os pais e a comunidade, a troca de experiências entre as escolas e a criação de comunidades colaborativas de aprendizagem (ALMEIDA, 2008, p. 63).

A modalidade adotada em todos os cursos foi a semipresencial, envolvendo atividades presenciais e a distância. Esta modalidade, também conhecida como ou b-learning (blended learning), tem sido muito utilizada nas formações do ProInfo Integrado, apresenta é considerada por Coutinho e Junior (2007, p. 11) como eficaz, na medida em que permite a flexibilidade mútua, tanto para os alunos como para os professores ao buscar combinar formação on-line e presencial, conforme as necessidades específicas de cada grupo.

Nesta direção, concordamos que os cursos a distância podem se constituir como experiências novas e desafiadoras para os cursistas. Porém, nem todos os professores que atuam 


\section{HORIZONTES - REVISTA DE EDUCAÇÃO}

e-ISSN: 2318-1540

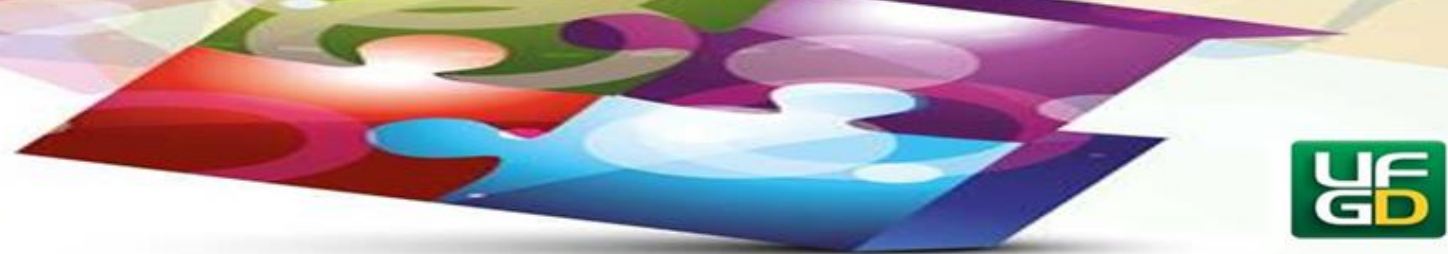

na educação básica receberam formação inicial e/ou continuada que os habilite a aprender neste novo contexto. Assim, surge um grande desafio quando se propõe a formar professores que não apresentam familiaridade com os ambientes digitais em cursos a distância e outros com diferentes níveis de apropriação das tecnologias.

Os cursistas com mais facilidade em dominar os aparelhos, certamente terão melhores condições de continuar aprendendo e com isso, incorporar estes conhecimentos a sua prática. Por outro lado, há aqueles que requerem uma maior atenção e "necessitam de muito estímulo, apoio, estratégias intensivas e diferenciadas para provocar o desejo de interagir e conhecer os ambientes" (BONILLA, 2010, p. 49).

É preciso investir em modelos diferenciados de formação de professores que favoreçam a curiosidade e atitudes positivas diante das TIC. Modelos formativos que fossem ao encontro das necessidades destes professores.

A partir do momento em que os professores se inscrevem nestes cursos por meio do ambiente virtual do E-proinfo (ambiente colaborativo de aprendizagem), os professores têm acesso aos materiais multimídias, postam atividades e podem interagir com outros colegas. Este um espaço se torna propício porque favorece a criação de comunidades virtuais de aprendizagem que permitem o trabalho colaborativo.

Nestas comunidades podem ocorrer aprendizagens autênticas, visto que os problemas trazidos pelos seus membros, não são apenas exemplos, mas problemas presentes no interior das escolas. Os professores podem encontrar nestas comunidades, possibilidades de operar de modo colaborativo e abordar tarefas em equipe ou aprender novas formas de trabalhar.

As interações ocorridas nos ambiente virtuais propiciam "a construção de comunidades de aprendizagem que ultrapassem os muros das escolas e, consequentemente, ampliam o escopo da reflexão e de compreensão sobre a prática integrada do uso das tecnologias e das mídias na escola" (PRADO; SILVA, 2009, p. 64). Por isso, é preciso criar um ambiente escolar na qual haja o fomento ao trabalho interdisciplinar a fim de que os professores entre si tanto dentro quanto fora da escola.

\section{Ações formativas voltadas para as tecnologias móveis na escola}




\section{HORIZONTES - REVISTA DE EDUCAÇÃO}

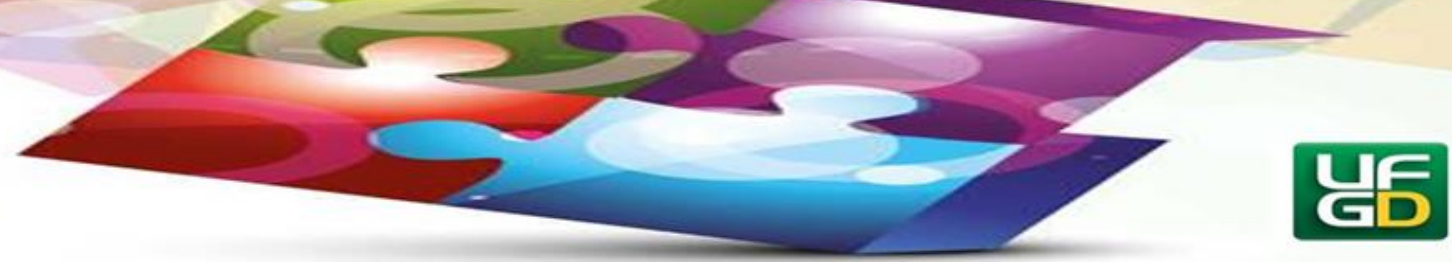

No levantamento desenvolvido, buscamos identificar as ações de formação continuada sobre as tecnologias móveis na escola. Localizamos o Projeto Educação Digital, o PROUCA e a Oficina Uso pedagógico do tablet.

O Projeto Educação Digital previa a instalação da lousa digital nas escolas e a entrega de tablets para professores do Ensino Médio. O Projeto Educação Digital previa a inclusão de tecnologias de informação e comunicação no processo de ensino, por meio da distribuição dos equipamentos tecnológicos nas escolas e da oferta de conteúdos e recursos multimídia e digitais.

O PROUCA ${ }^{4}$ consiste em um programa que tem como foco a prática pedagógica permeada pelo uso do laptop educacional por meio da distribuição destes equipamentos para cerca de 300 escolas do país. Tendo em vista habilitar os professores a ensinar mediante o uso dos laptops em suas aulas, foi oferecida uma formação de 180 horas.

O documento Formação Brasil - projeto, planejamento das ações/cursos reforça a necessidade do compromisso de uma efetiva política de formação de gestores e professores por meio da parceria firmada entre instituições de ensino superior, núcleos de tecnologia educacional, professores e alunos monitores que formariam uma rede de cooperação e colaboração (BRASIL, 2009).

Observamos alguns pressupostos norteadores do projeto, tais como o aprendizado de novas ações pedagógicas com o apoio da tecnologia que conduza a mudanças no currículo escolar; a escola como espaço privilegiado para a aprendizagem e inclusão digital das classes menos favorecidas; respeito e autonomia; organização curricular de acordo com as características e experiências dos alunos (PROUCA, 2010). A escola, neste contexto, se configura como uma organização aprendente e o professor como mediador do conhecimento. A formação dos professores, sugerida pelo PROUCA se dá em serviço ou na ação, de acordo com a realidade da sala de aula e nos experimentos do uso dos laptops (BRASIL, 2009).

Outro ponto a ser destacado é a criação de uma rede de apoio às escolas por meio da implementação do PROUCA. Com isso, seriam criados subsídios para a "ampliação do projeto nas demais escolas da rede pública de educação básica” (BRASIL, 2009, p. 2).

\footnotetext{
${ }^{4} \mathrm{O}$ município na qual realizamos o estudo não foi contemplado com o PROUCA, mas analisamos o material utilizado nas escolas pelas quais foi implantado a fim de conhecermos as suas contribuições para a melhoria do trabalho docente.
} 


\section{HORIZONTES - REVISTA DE EDUCAÇÃO}

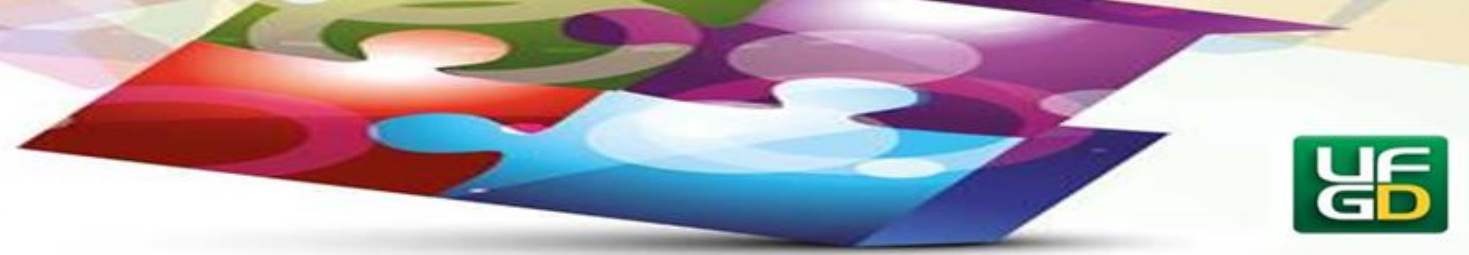

A formação do PROUCA compreende cinco módulos que envolvem a parte técnica quanto ao uso dos laptops nas escolas e a socialização de atividades relacionadas ao uso destes recursos pelos professores, totalizando 180 horas distribuídas em módulos de 3 módulos de 40 horas e 2 de 30 horas.

O primeiro módulo é composto de textos basicamente técnicos (manuais e tutorias) que favorecem a apropriação técnica dos laptops. O segundo módulo versa sobre a web 2.0 e das suas possibilidades pedagógicas. O terceiro módulo demonstra exemplo de situações de aprendizagem baseadas na "problematização ou pedagogia problematizadora e aprendizagem por desafios lógicos" (JESUS, 2013, p. 61). O quarto módulo se caracteriza pelo estudo e implementação de projetos atrelados ao currículo da escola, sendo proposto aos professores que desenvolvam "projetos de trabalhos articulados ao currículo, integrando as tecnologias e recursos do laptop" (JESUS, 2013, p. 61). No quinto módulo há a “organização de seminários pelas IES Local para discussão e socialização das ações realizadas pelas escolas inseridas no PROUCA" (JESUS, 2013, p. 61).

A concepção pedagógica do PROUCA, segundo Jesus (2013, p. 61) demonstra "uma formação aberta com possíveis diálogos e caminhos a serem explorados pelos professores e gestores", pois pressupõem a interrelação entre os módulos de modo a atender às necessidades dos envolvidos no programa. Há uma "proposta flexível que respeita a autonomia da organização curricular, a realidade e as experiências de todos os envolvidos no processo educacional" fato que favorece a integração do laptop ao currículo (JESUS, 2013, p. 61).

A metodologia da formação do PROUCA contempla três dimensões que se interrelacionam: a tecnológica que se refere à apropriação e ao domínio dos recursos tecnológicos sobre o uso do Linux Educacional e dos aplicativos presentes nos laptops; b) a pedagógica que está relacionada ao uso dos laptops nos processos de ensino e aprendizagem, assim como "na gestão do tempo e do espaço e nas relações entre os protagonistas da escola, do sistema de ensino e da comunidade externa" (BRASIL, 2009, p. 9); c) a teórica visa articular teorias educacionais que possibilitem a compreensão crítica dos usos das tecnologias em contextos distintos, tendo em vista a reconstrução tanto da prática docente quanto da escola.

Por meio da formação, os professores podem promover práticas inovadoras que contribuam para aprendizagens baseadas na cooperação mediante a utilização do laptop educacional, tendo em vista mudanças no currículo das escolas. Em se tratando dos resultados 


\section{HORIZONTES - REVISTA DE EDUCAÇÃO}

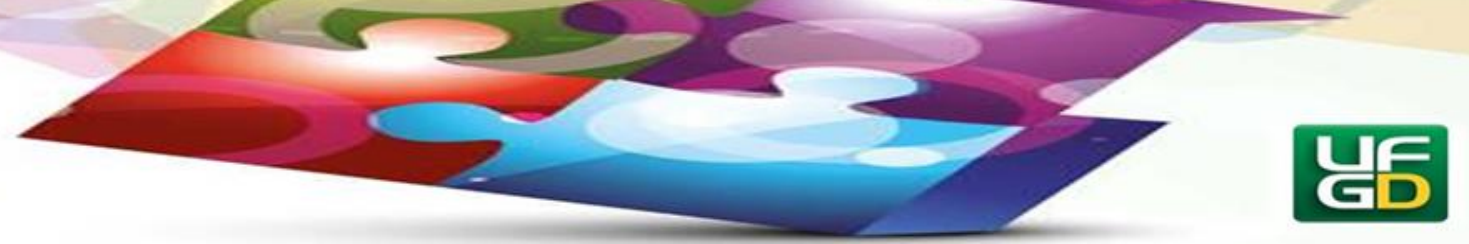

destas formações Valente e Martins (2011) concluem que houve a criação de novas possibilidades pedagógicas com a inserção dos laptops nas escolas. Todavia, a simples adoção destes equipamentos não implica, necessariamente, em mudanças significativas nas práticas docentes. Tais ações teriam maior êxito se garantissem a infraestrutura, equipamentos e internet necessários para que gestores, professores e alunos se apropriassem dos mesmos, bem como promovessem alterações profundas nos tempos e espaços escolares (BRASIL, 2009, p. 6).

O professor não faz nada sozinho. Neste sentido, Bonilla e Pretto (2015, p. 510) alertam que tecnologias como o laptop educacional continuem sendo utilizadas como ferramentas auxiliares aos processos educacionais na medida em que

[...] busca-se transformá-lo em uma máquina pedagógica em vez de máquina de comunicação e de produção de sentidos, sua principal característica e função; uma máquina que possibilita que essas ações sejam feitas de forma descentralizada, ou seja, "quebrando" as barreiras e o isolamento da escola.

O laptop deveria ser visto "como elemento de informação, de comunicação e de produção de imagens, informações e conhecimentos" (BONILLA; PRETTO, 2015, p. 510).

Os gestores também devem receber formação a fim de que sejam capazes de alterar os currículos das escolas, como estudos analisados por Valente e Martins (2011, p. 135) em escolas ligadas à Universidade Estadual de Campinas (UNICAMP), apontam que houve uma apropriação dos laptops por parte dos professores que participaram das formações e "começam a perceber os potenciais dos laptops e os diferentes recursos que podem ser utilizados em atividades em diferentes espaços da escola e explorando diferentes conteúdos curriculares”.

Localizamos apenas uma ação de formação voltada para o uso de tecnologias móveis no município na qual realizamos a pesquisa, a Oficina Uso pedagógico do tablet que contava com uma carga horária de 20 horas. Era destinada a professores gerenciadores das tecnologias educacionais e de recursos midiáticos (PROGETEC) dos municípios sob a jurisdição do NTE de Naviraí - MS que são responsáveis pela formação sobre as tecnologias digitais e móveis das escolas em que atuam. Vale destacar que, não obtivemos informação se esta oficina foi ministrada nas escolas ou quais foram contempladas.

De acordo com o projeto da oficina, há tópicos que abrangem o uso dos tablets e seus aplicativos com vários sites e blogs pelos quais os professores podem acessar para desenvolver as atividades previstas. São apresentados vários sites com tutoriais com as características deste 


\section{HORIZONTES - REVISTA DE EDUCACÃOO}

e-ISSN: 2318-1540

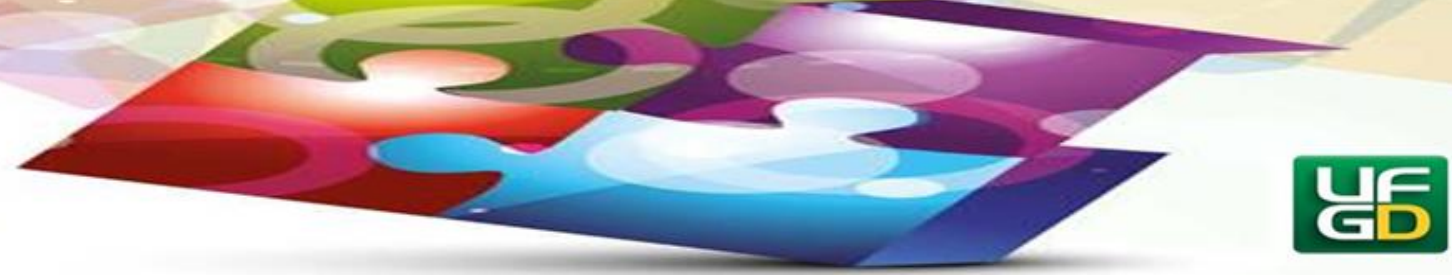

aparelho. De modo geral, os sites estão ligados ao Ministério da Educação, tais como Portal do Professor, Domínio Público e Fundo Nacional de Desenvolvimento da Educação (FNDE). A sua avaliação consistiu na elaboração de uma aula utilizando aplicativos postagem da mesma no Portal do Professor.

Consideramos que apenas uma oficina com carga horária limitada que faz alusão apenas a parte técnica dos equipamentos sem se preocupar com algum tipo de abordagem pedagógica em torno de seu emprego em sala de aula se mostra insuficiente para a formação docente.

Ao analisar as ações dos NTE localizamos alguns estudos que observaram discrepâncias quanto a sua atuação que varia de um estado para outro, de acordo com as orientações do ProInfo. Segundo Bonilla (2012) e Martins e Flores (2015) necessitam auxiliar as escolas no processo de incorporação das TIC em atividades pedagógicas. Contudo, não se conseguido cumprir efetivamente o seu papel de promover a introdução dos professores na cultura digital.

\section{Considerações Finais}

Tendo em vista identificar e analisar as ações de formação continuada do ProInfo Intregrado ofertadas pelo Núcleo de Tecnologia Educacional do município de Naviraí- MS que possibilitassem a integração de tecnologias móveis no processo de ensino e aprendizagem, localizamos os principais cursos oferecidos pelo Núcleo de Tecnologia Educacional do município de Naviraí - MS, no período de 2009 a 2014, a saber: Introdução à Educação Digital, Tecnologias na Educação: Ensinando e aprendendo com as TIC, Elaboração de Projetos, Redes de Aprendizagem. Quanto ao uso das tecnologias móveis, o NTE ofertou a Oficina Uso pedagógico do tablet.

Com base nos resultados do estudo, observamos que estas ações pretendem dotar gestores e professores de conhecimentos necessários para se apropriarem das tecnologias digitais e móveis e com isso, integrá-las no trabalho docente. Os resultados demonstram que estas ações pretendem dotar gestores e professores de conhecimentos necessários para se apropriarem das tecnologias a fim de integrá-las no trabalho docente. Porém, são pensadas em nível nacional, na modalidade semipresencial, desconsiderando a realidade e peculiaridade das escolas instituições, bem como os variados níveis de apropriação dos participantes. 


\section{HORIZONTES - REVISTA DE EDUCAÇÃO}

e-ISSN: 2318-1540

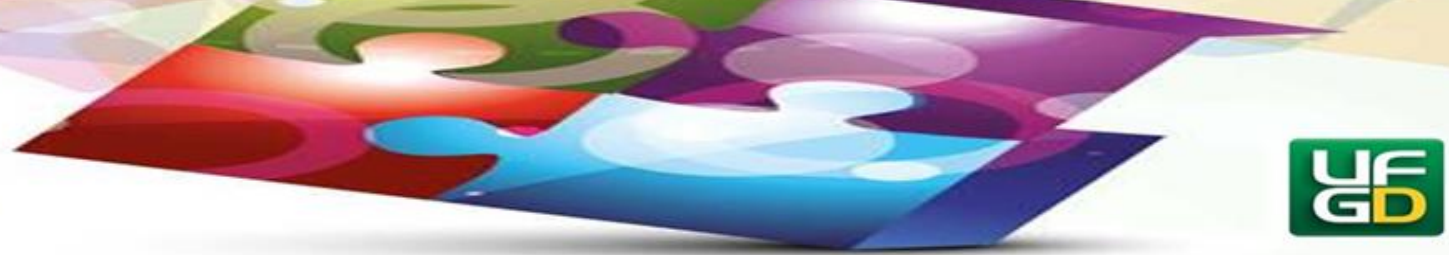

Recomendamos a instauração de propostas formativas que considerem as demandas provenientes das instituições e as necessidades dos professores e que estejam ligadas à realidade pela qual estão inseridos.

No que se refere às tecnologias móveis, concluímos que não há propostas consistentes que dotem os professores de conhecimentos necessários para utilizar celulares, tablets e laptops em situações pedagógicas. Além das políticas públicas de infraestrutura a formação docente precisa considerar o lócus de atuação dos professores, tomando-os ao mesmo tempo objetos e sujeitos de sua formação" (CARVALHO, 2017, p. 295). É importante que esta formação que se dê com base no perfil da instituição pela qual docente pertence, com o apoio de outros agentes como os professores responsáveis pelas salas de tecnologias e gestores e/ou em parceria com universidades. Este trabalho poderia "envolver os docentes de acordo com os níveis de ensino, as disciplinas que ministram, os turnos etc., a fim de que em contato com seus pares pudessem pensar em como instaurar novas práticas pedagógicas” (CARVALHO, 2017, p. 295).

\section{Referências}

ALMEIDA, Maria Elizabeth B; SILVA, Maria da Graça Moreira da. Currículo, Tecnologia e Cultura Digital: Espaços e Tempos de Web Currículo. Revista e-curriculum, São Paulo, v. 7. n. 1. abril/2011.

BORGES, Marilene Andrade F.; FRANÇA, George. O uso das tecnologias móveis na escola: uma nova forma de Organização do trabalho pedagógico. XVI ENDIPE Encontro Nacional de Didática e Práticas de Ensino - UNICAMP - Campinas. 2012.

ARRIADA, Monica Carapeços; RAMOS, Edla Maria Faust. Redes de Aprendizagem. Guia do Formador. 1. ed. Brasília: Ministério da Educação, Secretaria de Educação Básica, 2013.

BONILLA, Maria Helena Silveira. Políticas Públicas para inclusão digital nas escolas. Motrivivência. ano XXII, n. 34. p. 40-60. jun. 2010.

A presença da cultura digital no GT Educação e Comunicação da ANPED. Revista Teias. v. 30. 71-93. Set/dez. 2012.

PRETTO, Nelson De Luca. Política educativa e cultura digital: entre práticas escolares e práticas sociais. Perspectiva. v. 33, n. 2, p. 499 - 521, maio/ago. 2015.

BRASIL. Ministério da Educação. Programa um Computador por Aluno - UCA. Secretaria de Educação a Distância, 2009. Formação Brasil: projeto, planejamento das ações/cursos, p. 136, 2009. Disponível em: 


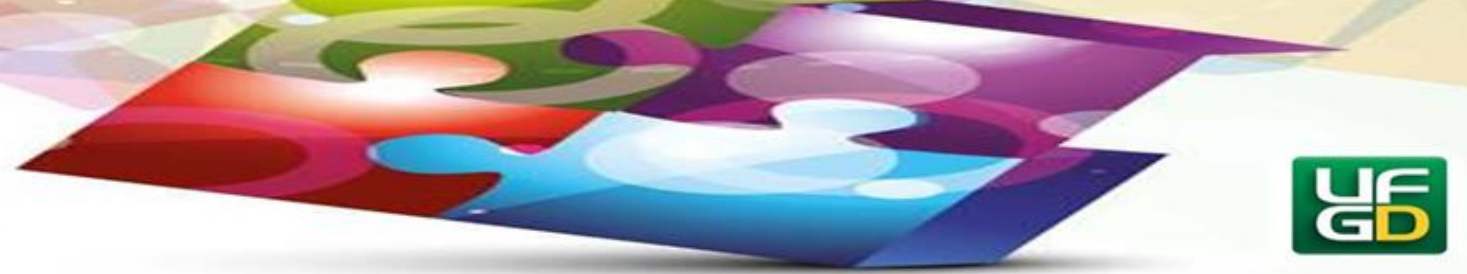

http://www.virtual.ufc.br/cursouca/modulo_apresentacao/topico_03/processo_formativo/f ormacao_brasil.pdf $>$. Acesso em: maio 2015.

BRASIL. Ministério da Educação. Implantação e desenvolvimento dos projetos-piloto em escolas públicas para o uso pedagógico do laptop educacional conectado. Termo de referência. Secretaria de Educação a Distância, p. 1-22, ago. 2010. Disponível em: ramec.mec.gov.br/index.php?option=com_docman\&task. Acesso em: Jun. 2011.

CARVALHO, Célia Regina de. As tecnologias móveis na escola e o trabalho docente: as contribuições de uma pesquisa intervenção na formação continuada de professores da educação básica. Presidente Prudente: 2017, 337 p.

COUTINHO, Clara Pereira; BOTTENTUIT JUNIOR, João Batista. A complexidade e os modos de aprender na sociedade do conhecimento. 2007.

IBGE. Pesquisa nacional por amostra de domicílios: síntese de indicadores 2015 / IBGE, Coordenação de Trabalho e Rendimento. - Rio de Janeiro: IBGE, 2016. 108p.

JESUS, Ana Maria Ribas de. Programa um computador por aluno - Prouca: formação e prática docente. Campo Grande - MS, 2013. 128p. Dissertação (Mestrado em Educação). Universidade Católica Dom Bosco.

MARTINS, Ronei Ximenes; FLORES, Vânia de Fátima. A implantação do Programa Nacional de Tecnologia Educacional (ProInfo): revelações de pesquisas realizadas no Brasil entre 2007 e 2011. Revista Brasileira de Estudos Pedagógicos, v. 96, n. 242, 2015.

PRADO, Maria Elisabete Brisola Brito; SILVA, Maria da Graça Moreira da. Formação de educadores em ambientes virtuais de aprendizagem. Em aberto. Brasília. v. 22. n. 79. p. 6174. jan. 2009.

PRETTO, Nelson de Lucca. Redes colaborativas, ética hacker e educação. Educação em Revista, Belo Horizonte, v. 26, n. 3, p. 305-316, dez, 2010. Disponível em:

http://www.scielo.br/pdf/edur/v26n3/v26n3a15.pdf. Acesso em: 24 fev. 2014.

TARDIF, Maurice; LESSARD, Claude. O trabalho docente: elementos para uma teoria da docência como profissão de interações humanas. Petrópolis: Editora Vozes, RJ. 2. ed. 2005.

TARDIF, Maurice; LESSARD, Claude. Saberes docentes e formação profissional. Rio de Janeiro: Vozes, 5 ed. 2005.

SANTOS, Vanderlei Siqueira dos. Formação de professores na modalidade presencial e on-line com foco na prática pedagógica com a utilização das TICS. Tese de Doutorado. Pontifícia Universidade Católica do Paraná. 2012, 278 p. 


\section{HORIZONTES - REVISTA DE EDUCAÇÃO}

e-ISSN: 2318-1540

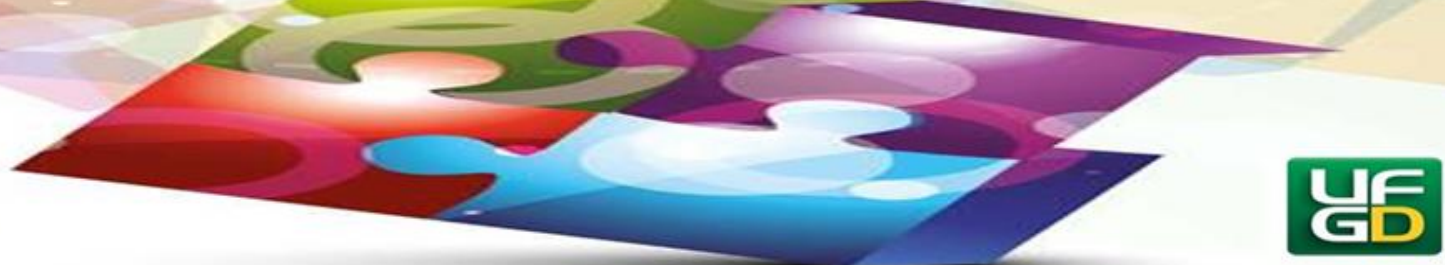

VALENTE, José Armando. MARTINS, Maria Cecília. O Programa Um Computador por Aluno e a Formação de Professores das Escolas Vinculadas à Unicamp. Revista Geminis. Ano2. n. 1. 2011. p. 116-136.

Enviado: 19/12/2018.

Aceito: 24/05/2019. 